\title{
Resíduos sólidos urbanos: viabilidade técnica do processo produtivo do biometano
}

\section{Rayme Vasconcellos Soares ${ }^{1}$ e Jerisnaldo Matos Lopes ${ }^{2}$}

${ }^{1}$ Faculdade Metropolitana de Camaçari. Avenida São Rafael, S/№. São Marcos. Salvador-BA, Brasil (CEP 41253-900). E-mail: raymesoares@gmail.com.

${ }^{2}$ Faculdade de Tecnologia e Ciências de Salvador. Curso de Mestrado Profissional Tecnologias Aplicáveis à Bioenergia. Rua Luís Viana Filho, 8812. Pituaçu. SalvadorBA, Brasil (CEP 41741-590).

Resumo. Fazendo uso das abordagens qualitativa e quantitativa, este trabalho é lastrado em investigação bibliográfica e documental, empregando a pesquisa exploratória e explicativa, de modo a possibilitar a análise da viabilidade técnica do processo produtivo do biometano a partir de resíduos sólidos urbanos, considerando o aterro sanitário como estrutura fundamental para a disposição dos resíduos, matéria-prima básica para o processo de produção do biogás. Há de se validar, contudo, a eficiência de um aterro sanitário projetado adequadamente, cuja composição possui, dentre outros elementos o sistema de drenagem de águas, o sistema de drenagem de gases, a camada de cobertura e um sistema de monitoramento, que visa a garantir a preservação do meio ambiente, a salubridade da população em torno e a segurança da obra, basicamente. O biometano é resultado da purificação do biogás que compreende a dessulfurização, o processo de secagem e a remoção do $\mathrm{CO}_{2}$, visando a alcançar um teor de metano de mais de $95 \%$.

Palavras-chave: Resíduos; Aterro sanitário; Biogás; Biometano.

Abstract. Urban solid waste: Technical feasibility of the biometric production process. Using qualitative and quantitative approaches, this work is weighed in bibliographical and documentary research, using the exploratory and explanatory research, in order to allow the analysis of the technical viability of the biomethane production process from urban solid waste, considering the sanitary landfill as a fundamental structure for the disposal of waste, basic raw material for the biogas production process. However, the efficiency of a properly designed landfill, whose composition has, among other elements, the water drainage system, the gas drainage system, the cover layer and a monitoring system, should be validated. the preservation of the environment, the salubrity of the surrounding population and the safety of the work, basically. Biomethane is the result of the biogas purification comprising desulphurisation, the drying process and the removal of $\mathrm{CO} 2$, aiming to achieve a methane content of more than $95 \%$.

Recebido:

$04 / 12 / 2018$

Aceito:

19/04/2019

Publicado:

30/04/2019

Acesso aberto

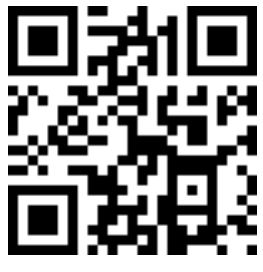

ORCID

(1) 0000-0001-7798-6355 Rayme Vasconcellos Soares

D 0000-0001-6926-6200 Jerisnaldo Matos Lopes 
Keywords: Waste; Landfill; Biogas; Biomethane.

\section{Introdução}

O Brasil é um contribuinte efetivo para o quadro de descuido com o meio ambiente, no que se refere ao tratamento dos resíduos, assim como demais setores de saneamento. Conforme registro da Associação Brasileira de Empresas de Limpeza Pública e Resíduos Especiais (ABRELPE, 2014), no país os recursos aplicados pelos municípios para custear os serviços de limpeza urbana e manejo de resíduos sólidos pouco aumentaram ao longo dos anos. É importante, no entanto, destacar que do tratamento dos resíduos sólidos urbanos (RSU), obtémse matéria-prima para a produção do biogás/biometano.

0 biometano é um biocombustível oriundo de biomassa e, desta forma, trata-se de uma fonte de energia renovável, ainda não utilizada em escala comercial, sendo assim, faz-se necessária, inicialmente, a análise da viabilidade técnica. Para o entendimento dos processos de produção do biogás/ biometano é importante delimitar os sistemas e subsistemas da referida produção e das operações a ela inerentes.

A coleta e a destinação/ disposição adequadas contribuem para a melhor qualidade ambiental, e culmina em uso otimizado do resíduo sólido orgânico decorrente das áreas urbanas. 0 lixo, gerado nos estados brasileiros, denota um potencial produtivo bastante considerável. De acordo com a forma nacional de caracterização de resíduos, constante na versão preliminar do PNRS, mais de $50 \%$ do total de resíduos sólidos urbanos produzidos no Brasil é de composição orgânica (MMA, 2017). Calderone (1999), em seus estudos, aponta que, do lixo coletado no país, $60 \%$ é de origem orgânica.

A disposição final adequada dos RSU se dá quando esta ocorre nos aterros sanitários, uma vez que estes atendem aos critérios de proteção e preservação ambiental e de saúde pública. Conforme Caldas (2011), nos aterros sanitários ocorre o processo de digestão anaeróbica dos RSU, onde são produzidos o biogás, o lixiviado e a matéria orgânica estabilizada.

\section{Aterro sanitário}

Conforme Elk (2007), o aterro sanitário é o resultado de uma obra de engenharia, cujo projeto atende a critérios técnicos, com o objetivo de, efetivamente, possibilitar a disposição dos resíduos sólidos urbanos, sem causar danos à saúde pública e ao meio ambiente.

Para a elaboração de um projeto de aterro sanitário para resíduos sólidos de Classe II (não perigosos), faz-se necessário o atendimento à norma de NBR 8419 NB 843, estabelecida pela Associação Brasileira de Normas Técnicas (ABNT, 1992), que faz referência às diretrizes técnicas dos elementos básicos de projetos de aterros, como, impermeabilização da base e superior, monitoramento ambiental e geotécnico, sistema de drenagem de lixiviados e de gases, exigência a respeito de células específicas para resíduos de serviços de saúde, disponibilização do manual de operação do aterro, bem como a definição a respeito do uso futuro da área do aterro, pós-atividades.

Conforme Carvalho et al. (2008), o aterro sanitário é contextualizado, habitualmente, como um reator bioquímico de grandes proporções que tem resíduos e água como importantes produtos de input e, gás e lixiviados, como produtos de output. No que se refere ao projeto de construção de um aterro sanitário, segundo Nascimento (2007), deve haver o seguinte conjunto de componentes: divisão em células, compactação de resíduos, cobertura, sistema de impermeabilização do solo de 
fundação, sistema de coleta e drenagem de líquidos e gases, tratamento do lixiviado, monitoramento geotécnico e ambiental, entre outros.

De acordo com Naime (2012), a preparação se efetiva com a impermeabilização e o nivelamento do terreno, com obras de drenagem que visam a impedir que a percolação, na massa dos resíduos depositados (lixo), atinjam as águas pluviais e, desta forma, aumente o volume de chorume a ser tratado. No setor de execução, os resíduos são discriminados conforme as suas características, e dispostos separadamente. $\mathrm{Na}$ conclusão do processo, momento em que é atingida a capacidade de disposição final de um setor do aterro sanitário já esgotado, um selamento com manta de polietileno de alta densidade, é feito. Acima é colocada uma camada de matéria orgânica onde são plantadas gramíneas.

Na Figura 1, podem-se verificar, em uma configuração básica, os sistemas inerentes ao funcionamento de um aterro sanitário, que se distribuem em três setores identificados, neste trabalho, pelas letras maiúsculas A (setor em preparo), B (setor em execução) e C (setor concluído).

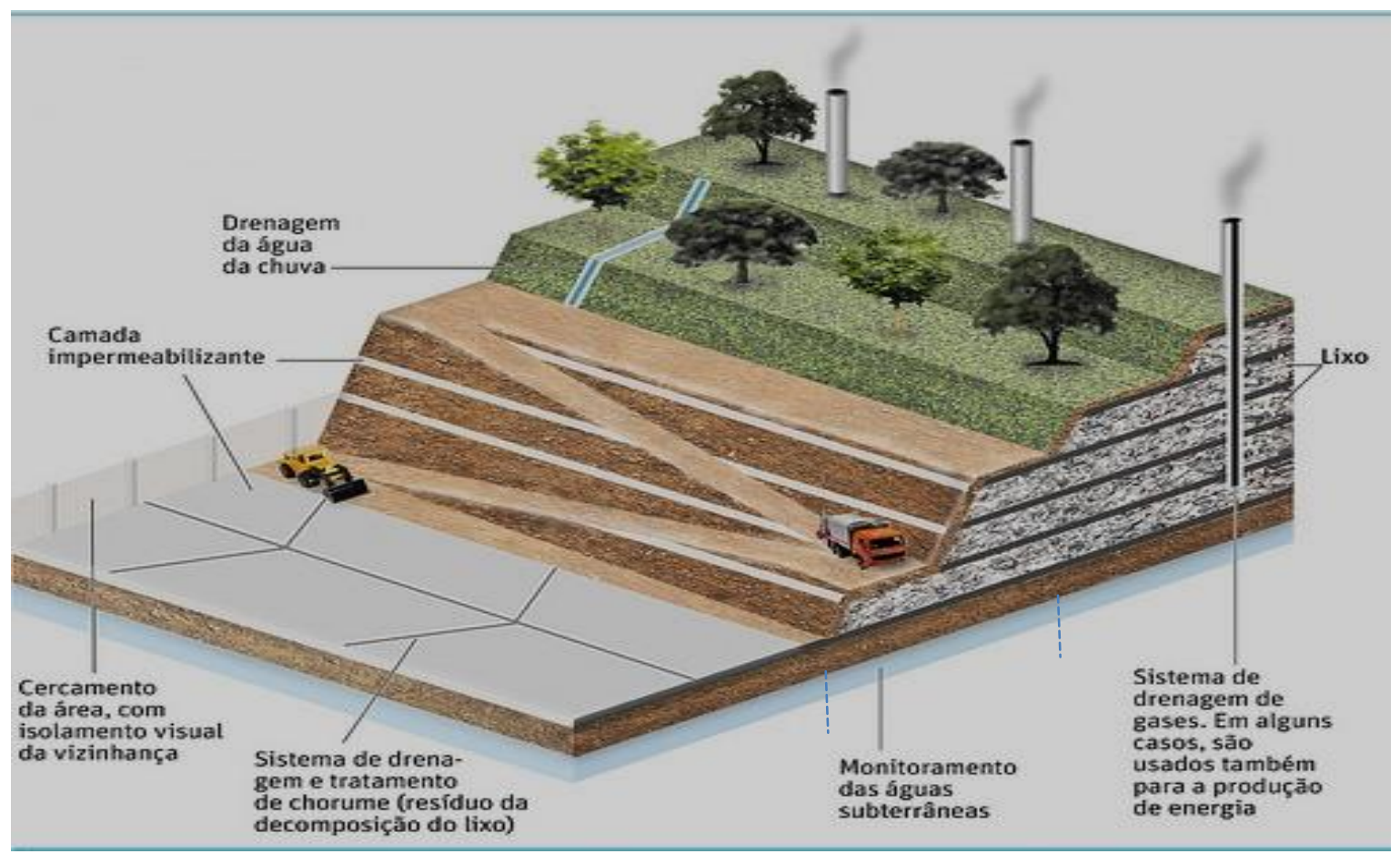

Figura 1. Configuração básica de um aterro sanitário. Fonte: Adaptado pelos autores, a partir de GRALTEC (2016).

A estrutura do aterro deve possuir drenos de gás, que liberam o metano e o gás carbônico; além disso, são utilizadas técnicas de monitoramento durante e após o seu fechamento.

\section{Elementos de um projeto de aterro sanitário}

Um aterro sanitário é composto por uma estrutura de considerável complexidade técnica, que possibilita um 
processamento eficiente dos resíduos depositados.

\section{Sistema de drenagem das águas \\ $\mathrm{Na}$ Figura 1, setor $\mathrm{C}$, pode-se} verificar a ilustração de como se dá um sistema de drenagem das águas da chuva. Conforme Elk (2007), a função deste sistema é impedir que ocorra entrada de água de escoamento superficial, no aterro, pois, esta infiltração, além de aumentar o volume de lixiviados, pode resultar na instabilidade da massa de resíduos pelas poro-pressões induzidas. A escolha do local e dimensionamento do sistema de drenagem superficial resultam dos dados adquiridos com base em levantamentos topográficos $\mathrm{e}$ climatológicos.

\section{Sistema de impermeabilização de fundo e de laterais \\ Visando à proteção e ao} impedimento de percolação do chorume para o subsolo e aquíferos, é feita a impermeabilização. A exigência mínima para a contenção de lixiviados não perigosos no Brasil é que as camadas de fundo e laterais consistam de uma camada simples, que pode ser de argila compactada de permeabilidade inferior a $10^{-7} \mathrm{~cm} / \mathrm{s}$, sendo, também, possível a utilização de geomembranas de polietileno de alta densidade (PEAD), cuja espessura mínima seja de $1 \mathrm{~mm}$. Com o propósito de reduzir os impactos ambientais e proporcionar durabilidade e segurança, deve-se atentar para a qualidade do material e dos métodos de construção (Elk, 2007).

Guedes (2007) salienta sobre a possibilidade de que, em substituição da camada de geotêxtil, seja utilizada uma camada de argila impermeável com altura aproximada de $50 \mathrm{~cm}$ (que pode variar em função de um estudo de permeabilidade, granulometria, compactação e umidade do solo). Do mesmo modo que a camada de geotêxtil, a camada de argila é indicada como proteção da geomembrana contra as ações mecânicas que, por ventura, possam danificá-la, resultando na perda da sua capacidade de estaqueamento.

Sistema de drenagem de lixiviados. A respeito do lixiviado, também chamado de chorume ou percolado, Elk (2007), diz:

Os lixiviados apresentam grande concentração de substâncias sólidas e alto teor de matéria orgânica. Esses líquidos, quando percolam através do substrato inferior do aterro sem que antes tenham passado por um processo de tratamento, contaminam os lençóis de água subterrâneos. Por essa razão, um sistema eficiente de drenagem é importante para evitar a acumulação de lixiviados dentro do aterro.

O dreno do lixiviado pode ser efetivado por meio de uma rede de drenos internos, constituídos, com frequência, de tubos perfurados, preenchidos com brita, cuja conformação é similar a uma "espinha de peixe", que conduzem o chorume drenado até um sistema de tratamento. 0 processo de drenagem deve acontecer acima da camada impermeabilizante inferior (Elk, 2007).

Sistema de drenagem de gases. 0 dreno de gases, decorrentes da decomposição da matéria orgânica, é o objetivo do sistema de drenagem de biogás. Desta forma, o referido sistema impede a migração de gases por entre os meios porosos constituintes do subsolo, o que poderia resultar no seu acumulo em fossas, poços, redes de esgoto e sob edificações, internas e externas ao aterro sanitário. (D'Almeida e Vilhena, 2000).

Usualmente, os drenos de biogás nos aterros sanitários se constituem de linhas de tubos perfurados, sobrepostos e envoltos por uma camada de brita, cuja espessura é igual ao diâmetro do tubo utilizado. Os referidos tubos atravessam a massa de resíduos aterrados no sentido vertical, e vão da base à superfície, 
formando uma chaminé (D'Almeida e Vilhena, 2000).

Conforme Guedes (2007), quando os aterros não possuem estruturação para o aproveitamento energético do biogás, este é diretamente lançado na atmosfera ou é queimado em um dispositivo simples para a sua ignição e queima (flare). Já os aterros, que utilizam de estruturas visando à produção de energia, possuem um sistema de captação do biogás. 0 biogás produzido é captado nesse sistema e encaminhado para uma estação de captação.

Cobertura (camada). Conforme Maciel (2003), a cobertura é um sistema que tem como característica servir de ligação entre o interior de um aterro e a atmosfera. Em função disto, é percebido como parâmetro fundamental para $\mathrm{o}$ controle de poluição do ar.

De acordo com Maciel (2003), a vegetação sempre relacionada com a parte externa das camadas, independentemente do sistema adotado, tem como objetivo evitar problemas de erosão e contração do solo. Boscov (2008), afirma que a combinação da camada argilosa, que costumeiramente possui coeficiente de permeabilidade menor ou igual a $1 \times 10^{-9} \mathrm{~m} / \mathrm{s}$, com a geomembrana possibilita a efetiva impermeabilização.

Monitoramento. Conforme Elk (2007), o sistema é composto de monitoramento ambiental e geotécnico, descrito no Tabela 1.

Tabela 1. Sistema de monitoramento.

\begin{tabular}{|c|c|}
\hline Monitoramento ambiental & Monitoramento geotécnico \\
\hline $\begin{array}{l}\text { Controle das águas superficiais, através de } \\
\text { análises físicas, químicas e bacteriológicas, em } \\
\text { pontos determinados tecnicamente, a montante } \\
\text { e a jusante do aterro; }\end{array}$ & $\begin{array}{l}\text { Inspeção visual - indícios de erosão e trincas e } \\
\text { fissuras, na camada de cobertura, ou qualquer } \\
\text { outro sinal do movimento da massa de resíduos; }\end{array}$ \\
\hline $\begin{array}{l}\text { Monitoramento de águas subterrâneas - } \\
\text { instalação de poços, a montante e a jusante no } \\
\text { sentido do fluxo do escoamento preferencial do } \\
\text { lençol freático; }\end{array}$ & $\begin{array}{c}\text { Deslocamentos verticais e horizontais - marcos } \\
\text { superficiais e inclinômetro; }\end{array}$ \\
\hline Estação pluviométrica - grandes aterros; & \multirow{3}{*}{$\begin{array}{l}\text { Medidas de pressões de gases e líquidos, no } \\
\text { interior do maciço - piezômetros. }\end{array}$} \\
\hline $\begin{array}{l}\text { Controle da qualidade do chorume, após o } \\
\text { tratamento, através de análises físico-químicas } \\
\text { para caracterização deste; }\end{array}$ & \\
\hline $\begin{array}{l}\text { Controle da descarga de líquidos lixiviados no } \\
\text { sistema de tratamento. }\end{array}$ & \\
\hline
\end{tabular}

Fonte: Elaborado pelos autores a partir de Elk (2007).

Vale ressaltar que além do monitoramento denominado ambiental e geotécnico, é de fundamental importância que haja controle dos resíduos, no que se refere às características físicas (análise gravimétrica, teor de umidade e densidade).
Futuro da área do aterro. De acordo com Castilho Junior (2003), o plano de um aterro deve ser simples, e contemplar todas as atividades operacionais rotineiras em um aterro, de modo a garantir que a operação seja segura e ininterrupta. A inadequação da operação pode resultar na transformação de um aterro sanitário em um lixão. 

-se que:

A respeito do futuro da área, tem-

Em um projeto de aterro sanitário deve estar previsto também o reaproveitamento da área após o encerramento de suas atividades ou o final de sua vida útil. É comum nesse tipo de área, a construção de parques de lazer para a comunidade, centros de treinamentos/ capacitação de trabalhadores, edificações de pequeno porte, novas urbanizações etc. 0 local pode ser usado tanto para o lazer quanto para a geração de empregos e renda para a comunidade, através de atividades ambientalmente corretas (Elk, 2007, p. 24).

Sendo assim, de nada vale um projeto de aterro sanitário que não vislumbre o uso adequado da área para este fim.

\section{Purificação do biogás}

O biogás compõe-se de muitos elementos, destacando-se, no entanto, o $\mathrm{CH}_{4}(50 \%$ a $75 \%)$ e o $\mathrm{CO}_{2}(25 \%$ a $45 \%)$. Ao passar por processo de limpeza e purificação, o biogás dá origem ao biometano:

Quando limpo e purificado, o biogás origina o biometano que pode substituir o gás natural em todas as suas utilizações comuns: produção de eletricidade, combustível de veículos e aquecimento (Monteiro, 2011).

O processo que se dá no biogás, transformando-o em biometano, objetiva, prioritariamente, a elevação da concentração de metano, por meio da remoção de $\mathrm{CO}_{2}$ juntamente com outros componentes (Veiga e Mercedes, 2015).

Conforme estudos, com os equipamentos utilizados para o funcionamento dos veículos com o GNV, atentando para peculiaridades exequíveis, o biogás processado, e transformado em biometano pode ser utilizado como biocombustível para veículos.

Qualquer veículo com um motor adaptado para funcionar a gás natural e com um tanque de armazenamento para suportar as pressões do combustível (200-250 bar) está automaticamente habilitado a usar biometano (Monteiro, 2011).

Segundo informações contidas do Projeto Brasil-Alemanha de Fomento ao Aproveitamento Energético de Biogás no Brasil (PROBIOGÁS, 2016), as mais importantes medidas para a purificação do biogás são a separação de dióxido de carbono e sulfeto do biogás, bem como o processo de secagem, visando a alcançar um teor de metano de mais de $95 \%$. Em primeiro lugar, aplicam-se procedimentos físicos, baseados em adsorção e absorção, refrigeração e separação por membranas, tal como etapas de absorção química. Com base ainda no PROBIOGÁS (2016), são diversos os processos utilizados para a dessulfurização, para a separação do dióxido de carbono e para a secagem. A seguir, conforme PROBIOGÁS (2016) estão discriminadas (conceituadas) as etapas de purificação.

\section{Dessulfurização}

Visando a assegurar o processo de enriquecimento do metano, a ação primeira é a dessulfurização. Para este fim podem ser utilizados processos biológicos ou de absorção química e de adsorção bem como processos de sorção catalítica. Há, ainda, a distinção entre os processos de dessulfurização grossa e fina.

A denominada dessulfurizaçao grossa evita que ocorram problemas em alguns dos componentes de instalação (como exemplo, na Central de Cogeração de energia elétrica - CHP). A presença, na ordem de algumas centenas de partes por milhão de sulfeto de hidrogênio, no biogás bruto, é considerável para gerar 
avarias no equipamento. Existe a possibilidade de a dessulfurização se efetivar na geração do biogás ou posteriormente a esta, fora do biodigestor. Para a extinção grossa de partículas de enxofre, pode-se destacar a dessulfurização biológica, no biodigestor, a limpeza bioquímica do biogás e a precipitação do sulfeto. No processo de dessulfurização fina, o enxofre é excluído até um teor limite de sulfeto de hidrogênio de $5 \mathrm{mg} / \mathrm{m}^{3}$, atendendo, desta forma, o que consta nas leis alemãs para a utilização do biometano, como gás, na rede de gás natural e o seu uso como combustível. Os baixos valores de $\mathrm{H}_{2} \mathrm{~S}$ no biogás podem ser obtidos através de processos de adsorção com carvão ativado, óxidos de zinco e óxidos de ferro.

\section{Secagem}

A secagem do biogás se faz necessária devido à possibilidade de corrosão em função do efeito de condensação de $\mathrm{H}_{2} \mathrm{O}$, e dos elementos que compõem o gás, $\mathrm{CO}_{2}$ e $\mathrm{O}_{2}$ no ambiente úmido. Para a secagem de biogás podem ser aplicados os processos de secagem por condensação, de adsorção com sílica gel e carvão ativado, e de lavagem com glicóis como processo de adsorção.

\section{Remoção de $\mathrm{CO}_{2}$}

Visando à concentração de metano, faz-se necessária a separação do $\mathrm{CO}_{2}$. Uma vez que o $\mathrm{CO}_{2}$ é a mais importante substância coadjuvante do biogás, dependendo da sua composição, a sua separação é fundamental para que, desta forma, aumente a concentração do $\mathrm{CH}_{4}$, obtendo-se, assim, as propriedades do gás que irão alimentar as redes de gás natural e o uso como combustível. São empregados, para este fim, os processos de adsorção (por variação de pressão), de absorção física e química, a separação por membranas, bem como processos criogênicos.

\section{Considerações finais}

As tecnologias utilizadas para a construção de um aterro sanitário asseguram o adequado processamento dos resíduos sólidos, resultando em produtos para utilizações diversas, e, mais especificamente o biogás, que dentre outras finalidades, é a matériaprima para biocombustível. Destaca-se o fato de ser um mecanismo eficiente que funciona sem agredir o meio ambiente onde está localizado.

O biogás deve passar por um processo de limpeza e purificação, transformando-se em biometano através de processamentos físicos e químicos. Desta forma, torna-se um biocombustível extremamente viável. As tecnologias de processamento são, comprovadamente, eficientes, resultando em uma alternativa ambientalmente e tecnologicamente adequada para o uso em veículos.

\section{Conflito de interesses}

Os autores declaram não haver conflito de interesses.

\section{Referências}

ABRELPE - Associação Brasileira de Empresas de Limpeza Pública e Resíduos Especiais. Panorama dos Resíduos Sólidos no Brasil. 2014. Disponível em: <http://www.abrelpe.org.br/Panorama/pan orama2014.pdf>. Acesso em: 01 jul. 2017.

ABNT - Associação Brasileira de Normas Técnicas. ABNT NBR 8419:1992 Apresentação de projetos de aterros sanitários de resíduos sólidos urbanos procedimento. Rio de Janeiro: ABNT, 1992.

Boscov, M. E. G. Geomecânica dos resíduos sólidos urbanos. In: Boscov, M. E. G. Geotecnia ambiental. 1. ed. São Paulo: Oficina de Textos, 2008. p. 31-62.

Caldas, A. S. Geração de metano devido à digestão anaeróbia de resíduos sólidos urbanos: estudo de caso do Aterro Sanitário Metropolitano Centro, Salvador-BA. Salvador: UFBA, 2011. (Dissertação de mestrado). 
Calderoni, S. Os bilhões perdidos no lixo. 4. ed. São Paulo: Humanistas/FFLCH/USP, 2003.

Carvalho, M. F., Machado, S. L., Nascimento, J. C. F., Caldas, A. S. Procedimento simplificado para obtenção de parâmetros de geração de metano em regiões tropicais. Anais do XIV COBRAMSEG - Congresso Brasileiro de Mecânica dos solos e Engenharia Geotécnica, Búzios, 2008.

Castilhos Junior, A. B. (Coord.). Resíduos sólidos urbanos: aterro sustentável para municípios de pequeno porte: projeto PROSAB. Rio de Janeiro: ABES, 2003.

D’Almeida, M. L. O.; Vilhena, A. Lixo municipal: manual de gerenciamento integrado. São Paulo: IPT/CEMPRE, 2000.

Elk, A. G. H.P. Redução de emissões na disposição final. In: Elk, A. G. H.P. Mecanismo de desenvolvimento limpo aplicado a resíduos sólidos. 1 . ed. Rio de Janeiro: IBAM, 2007.

GRALTEC Treinamentos. Solução de qualidade em cursos e treinamentos para o Universo GEO e Meio Ambiente. Como funciona um aterro sanitário e a que tipo de resíduos se direciona? Disponível em: $<$ http://graltec.com/como-funciona-umaterro-sanitario-e-a-que-tipo-de-residuos-sedireciona/>. Acesso em: 12 dez. 2017.

Guedes, V.P. Estudo do fluxo de gases através do solo de cobertura de aterro de resíduos sólidos urbanos. Rio de Janeiro: COPPE, UFRJ, 2007. (Dissertação de mestrado).

Maciel, F. J. Estudo da geração, percolação e emissão de gases no aterro de resíduos sólidos da Muribeca, PE. Recife: UFPE, 2003. (Dissertação de mestrado).
MMA - Ministério do Meio Ambiente. Política Nacional de Resíduos Sólidos. Brasília: MMA, 2014. Disponível em: <http://www.mma.gov.br/cidadessustentaveis/residuos-solidos/politicanacional-de-residuos-solidos>. Acesso em: 20 nov. 2017.

Monteiro, S.D.S.C. Produção de biometano: análise de mercado e estudo da separação por PSA. Porto: Universidade de Porto, 2011. (Dissertação de mestrado). Disponível em: <https://repositorioaberto. up.pt/bitstream/10216/69219/1/00015047 5.pdf>. Acesso em: 27 jun. 2017.

Naime, R. Destinação final em aterro sanitário. 2012. Disponível em: <https://www.ecodebate.com.br/2012/05/0 3/destinacao-final-em-aterro-sanitarioartigo-de-roberto-naime/>. Acesso em: 28 dez. 2017.

Nascimento, J. C. F. Comportamento mecânico de resíduos sólidos urbanos. São Carlos: EESC, USP, 2007. (Dissertação de mestrado).

PROBIOGÁS - Projeto Brasil-Alemanha de Fomento ao Aproveitamento Energético de Biogás no Brasil. Biometano como combustível veicular. Brasília: Ministério das Cidades, 2016. (Desenvolvimento do mercado de biogás, 5). Disponível em: <https://www.giz.de/en/downloads/giz_bio gas_como_combustivel_digital_simples.pdf>. Acesso em: 04 fev. 2018.

Veiga, A. P. B., Mercedes, S. S. Biometano de gás de aterros no Brasil: perspectivas. Anais do X Congresso sobre Geração Distribuída e Energia no Meio Rural, Universidade de São Paulo, São Paulo, 2015.

Informação da Licença: Este é um artigo Open Access distribuído sob os termos da Licença Creative Commons Attribution, que permite uso irrestrito, distribuição e reprodução em qualquer meio, desde que a obra original seja devidamente citada. 